Artvin Çoruh Üniversitesi

Orman Fakültesi Dergisi

ISSN:2146-1880, e-ISSN: 2146-698X

Yıl: 2017, Cilt: 18, Sayı:1, Sayfa:98-102

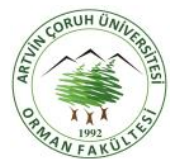

ofd.artvin.edu.t
Artvin Coruh University

Journal of Forestry Faculty

ISSN:2146-1880, e-ISSN: 2146-698X

Year: 2017, Vol: 18, Issue: 1, Pages:98-102

(c) (1)

\title{
Iki farklı ortamda katlama süresinin derici sumağı (Rhus coriaria I.) tohumlarının çimlenmesi üzerine etkisi
}

\section{The effects of stratification duration on germination of tanner's sumac (Rhus coriaria l.) seeds in two different environment}

Süleyman GÜLCÜ' ${ }^{1}$, Sevilay TARAMIŞ²

${ }^{1}$ Süleyman Demirel Üniversitesi, Orman Fakültesi, Orman Mühendisliği Bölümü, Isparta, Türkiye

${ }^{2}$ Süleyman Demirel Üniversitesi, Fen Bilimleri Enstitüsü, Isparta, Türkiye

Eser Bilgisi / Article Info

Araştırma makalesi / Research article

DOI: 10.17474/artvinofd.271043

Sorumlu yazar / Corresponding author

Süleyman Gülcü

e-mail: suleymangulcu@sdu.edu.tr

Geliş tarihi / Received

02.12.2016

Düzeltme tarihi / Received in revised form

16.03.2017

Elektronik erişim / Online available

23.03.2017

Anahtar kelimeler:

Derici Sumağı

Tohum

Katlama Süresi

Çimlenme Yüzdesi

Keywords:

Tanner's sumac

Seed

Stratification duration

Germination percentage

\section{Özet}

Bu çalışmada, Derici Sumağına (Rhus coriaria L.) ekimden önce uygulanabilecek katlama şekli ve süresinin tohumların çimlenmesi üzerindeki etkileri araştırılmıştır. Deneme Eğirdir Orman Fidanlığı'nda kurulmuştur. Bu kapsamda Bucak-Burdur orijinli tohumlar 2 farklı ortamda (açık hava koşullarında ve $+4^{\circ} \mathrm{C}$ de) 30,60 ve 90 günlük sürelerle katlamaya alındıktan sonra açık alan koşulları altında polietilen tüplere ekilmiştir. Elde edilen sonuçlara göre, en yüksek çimlenme (\%34) 5 nolu işlemde (açık hava koşullarında 90 gün katlama), en düşük çimlenme ise (\%17.5) 6 nolu işlemde $\left(+4^{\circ} \mathrm{C}\right.$ de 90 gün katlama) elde edilmiştir. Bu nedenle, erken ekim koşullarının mümkün olmadığı dönemlerde yeni ve daha güvenilir sonuçlar elde edilinceye kadar Eğirdir Orman Fidanlığında yürütülen sumak fidanı üretim çalışmalarında 5 nolu işlem önerilebilir.

\begin{abstract}
In this study, the effects of stratification treatments and periods could be applied before sowing and their periods on the germination of Tanner's sumac's (Rhus coriaria L.) seed were investigated. The experiment was established in Eğirdir Forest Nursery. Seeds from Bucak-Burdur were sown in polyethylene tubes after stratification for 30,60 and 90 days at 2 different environments (open field conditions and $+4^{\circ} \mathrm{C}$ in a refrigerator) under open field conditions in Eğirdir Forest Nursery. According to the results, the highest germination $(34 \%), 5^{\text {th }}$ process (stratification at open field conditions for 90 days), the lowest germination $\left(17.5 \%, 6^{\text {th }}\right.$ process (stratification at $+4^{\circ} \mathrm{C}$ for 90 days) were obtained. Therefore, until new and more reliable results are obtained during the periods when early sowing conditions are impossible, it can be suggested $5^{\text {th }}$ process for seedling production studies of Rhus coriaria in in Eğirdir forest nursery..
\end{abstract}

\section{Giriş}

Dünyanın dört bir tarafında ormanlık alanlar, açma yapılarak tarım, otlak ve yerleşim alanlarına dönüştürülmektedir. Bu durumun sonucu olarak da toprak ve su kaynakları tehlikeye düşmekte, çevresel sorunlarla iklim değişiklikleri ortaya çıkmakta ve çölleşmeye kadar varan büyük boyutlu sorunlarla karşılaşılmaktadır (Serez ve Eroğlu, 1993).

Çoğu ülkede olduğu gibi ülkemizde de ormanların büyük bir bölümü bugüne kadar çeşitli şekillerde tahribata uğradığından kendilerinden beklenen faydayı sağlayamamaktadır. Hiç kuşkusuz nüfusun hızla artışı ve orman alanlarının azalması, gelecekte odun hammaddesine olan gereksinimi daha da arttıracaktır.
Hem bu gereksinimin karşılanabilmesi hem de sanayileşme sonucu ortaya çıkan hava, kara ve su kirliliğinin giderilmesi için de daha çok yeşil alana yani ormana ve dolayısıyla daha çok ağaçlandırma çalışmalarına ihtiyaç duyulmaktadır (Yahyaoğlu 1997; Ürgenç 1998).

Tahrip olmuş orman sahalarını tekrar ormana kazandırmak, mevcut orman sahalarını genişletmek ormancılığın özellikle de silvikültürün en önemli görevidir. $\mathrm{Bu}$ görevin yerine getirilmesinde ağaçlandırma çalışmalarının önemi büyüktür. Ağaçlandırma çalışmalarında (gerek ekim gerekse dikim yoluyla) başarıyı arttırmada kullanılacak en etkili faktörlerden biri ağaçlandırma çalışmalarında kullanılacak türe ait 
tohumların özelliklerinin bilinmesidir. Bu nedenle de tohum özelliklerine yönelik araştırmalar ağaçlandırma faaliyetlerinin başarısı için büyük önem taşımaktadır (Yılmaz 1994).

Genetik özellikleri yüksek olan tohumları garanti altına aldığımızı varsaysak dahi, ilgili tür ada türlerin temel üretim materyali olan tohumlarının, çimlenme biyolojilerini ve fizyolojik gereksinimlerini bilmeden garanti altına almamı mümkün değildir. Tohumun çimlenme engeli, türlerin alansal ve iklimsel yayılışlarını en iyi şekilde kullanmalarını sağlayan önemli ekolojik bir faktördür. Çimlenme engeli zaman zaman kitlesel ve kaliteli fidan üretimi çalışmalarında bir engel olarak karşımıza çıkmaktadır (Rietveld 1989).

Çimlenme için gerekli çevresel faktörler su, sıcaklık, oksijen ve ışıktır. Tohumun su alması çimlenmenin ilk adımını oluşturmaktadır, bu nedenle çimlenme için ilk şart suyun varlığıdır. Çimlenmeye hazır tohum çimlenme için yeterli suyu almalıdır. Tohum içerisinde suyun hareketi çok yavaş ilerlemekte ve iç dokuların yeterli suya kavuşması uzun sürede olabilmektedir. Embriyo ve besin dokusunun yeterli suya kavuşma süresi türe göre değişmektedir. Tohumun su içeriği onun fizyolojik durumunun bir göstergesidir. Su içeriği tohumun katlama veya ekim için uygun şartlara sahip olup olmadığını göstermektedir veya tohumun yaşam göstergesini kaybetmeden saklanabilmesinin ve taşınabilmesinin göstergesi olabilmektedir (Bewley ve Black 1994; Leadem 1996). Özellikle küresel ısınma ve buna bağlı olarak ortaya çıkan iklim değişikliği sürecinde gerek değişik çevre koşullarına uyum sorunu olmaması, gerekse tıbbi aromatik türler arasında önemli bir yere sahip oluşu nedeniyle ağaçlandırma çalışmalarında karışıma katılabilecek önemli ve doğal türlerimizden biri de Derici Sumağı'dır. Tür, Akdeniz bölgesinde özellikle de BurdurBucak ve çevresinde yoğun olarak yayılış göstermekte olup, Eğirdir Orman Fidanlığı'nda yürütülen fidan üretim çalışmalarında çimlenme sorunları yaşanmaktadır. Bugüne kadar türün çimlenme engelinin giderilmesi konusunda laboratuvar ve sera koşullarında gerçekleştirilmiş bazı araştırma çalışmaları mevcuttur. Ölmez vd. (2007), 20 günlük soğuk katlamaya tabi tutulan Sumak tohumlarının sera koşullarında \%8.2'lik çimlenme yüzdesi elde ettiği, 60 günlük soğuk katlama +30 dakikalık sülfürik asit $\left(\mathrm{H}_{2} \mathrm{SO}_{4}\right)$ çözeltisinde bekletilerek bir ön işlem kombinasyonuna tabi tutulan sera koşullarında \%54.53, açık alan koşullarında ise \%39.78 çimlenme yüzdesi elde etmiştir. Yücedağ vd. (2010) yapmış oldukları çalışmada sera ve açık alan koşullarında farklı örtüleme şekli ile farklı ekim yöntemlerinin sumak tohumlarının çimlenmesi üzerine etkilerini araştırmışlardır. En yüksek çimlenme oranı "serada ekim+çift kat telisle örtüleme+polietilen tünele alma" örtüleme şekli, en düşük çimlenme oranını ise kontrol (örtülmemiş) ekiminde elde edilmiştir. Buna göre, ekimlerin sera koşullarında ve erken tarihte gerçekleştirilmesi ile üzerine telis örtülmesi ya da polietilen tünele alınması işlemlerinin birleştirilmesinin çimlenme oranına olumlu etkiler yaptığını tespit etmişlerdir.

Göktürk (2005), yapmış olduğu çalışmasında, çeşitli ön işlemleri takiben (sülfürik asit ile muamele, soğuk nemli katlama) Rhus coriaria tohumunu $30 \mathrm{dk}$. sülfürik asitte bekletme işleminden sonra 60 gün soğuk katlama işlemine tabi tutarak tohumları, açık alana ve sera ortamına ektiğinde, açık alanda en yüksek çimlenme yüzdesini \%54.5 olarak elde ederken sera koşullarında \%39.7 olarak tespit etmiştir.

Ayrıca, çimlenme kabiliyeti türler arasında farklılık gösterebileceği gibi aynı türde farklı yıllarda, farklı yörelerde hatta bazı türlerde aynı yetişme ortamındaki değişik bireyler arasında bile farklılık gösterebilmektedir. Bu nedenle bu çalışmada, ülkemizin değişik yörelerinde orman içinde ve dışında, münferit veya kümeler halinde doğal olarak yetişen derici sumağında tohumların çimlenme engelinin kaldırılmasında etkili olabilecek iki farklı ortamda katlama süresi araştırılmıştır.

\section{MATERYAL ve YÖNTEM}

Çalışmada materyal olarak, Bucak Orman işletme Müdürlüğü, Uğurlu Orman iş̧letme Şefliği çalışma alanında Derici Sumağı'nın küme veya münferit olarak yayılış gösterdiği bir alandan (enlem: $41^{\circ} 37^{\prime} 84^{\prime \prime}$ boylam: 2943'88" rakım: $1200 \mathrm{~m}$, bakı: kuzey) toplanan meyvelerden çıkarılan tohumlar kullanılmıştır. Üzerinde yeterince tohum bulunan 30 ağaç belirlenerek 2014 yılının Kasım ayı ortalarında, her birinden 500 g olgun 
meyve toplanmıştır. Toplanan meyveler Süleyman Demirel Üniversitesi Orman Fakültesi Laboratuvarında önce kaynar suya batırımış, daha sonra ezilerek tohumun meyveden ayrılması kolaylaştırılmıştır. Bu işlemleri izleyen süreçte de, ezilmiş tohumlu meyveler suda yüzdürülerek su üzerine çıkan meyve etinden tohumlar ayıklanmıştır.

Rastgele alınan $3 \times 30$ örnekte elektronik el kumpası ile meyve eni ölçümleri yapılmıştır. Meyvelerden elde edilen tohumlarda da bir kilogramdaki tohum sayısının belirlenmesi amacıyla rastgele alınan $3 \times 100$ tohum örneği tartılmıs ve bunlardan $3 \times 30$ tohumun eni yine dijital el kumpası ile ölçülmüştür. Bu tohumlar kesilerek tohum doluluk oranı belirlenmiştir. Yine ISTA (1996) kurallarına göre tohum 1000 tane ağırlığını belirlemek amacıyla $8 \times 100$ tohum örneği tartılmıştır.

Meyve ve tohum özelliklerinin belirlenmesinin ardından tohumlar hem açık alanda, hem de $+4^{\circ} \mathrm{C}^{\prime}$ de sırasıyla 30 , 60 ve 90 gün süreyle katlamaya alınmış ve Eğirdir Orman Fidanlığı açık alan koşulları altında ekilmiştir. Bu amaçla uygulanan işlemlere ilişkin ayrıntılar Tablo $1^{\prime}$ de verilmiştir. Deneme "Tesadüf Parselleri Deneme Desenine" uygun kurulmuştur. 7 işlem x 50 tüp x 4 yineleme $=1400$ tüp ve her tüpe birer tohum olacak şekilde ekim yapılmıştır. İşlemlerin ekim yastığı üzerindeki yerleri rastlantı kurallarına uygun olarak belirlenmiştir.

Tablo 1. Denemeye alınan işlemler ve ekim zamanları

\begin{tabular}{|c|c|c|}
\hline İşlem No & Uygulama şekli & Ekim Zamanı \\
\hline 1 & $\begin{array}{l}\text { Açık hava koşulları altında } 30 \text { gün } \\
\text { katlama* }\end{array}$ & 20 Ocak 2015 \\
\hline 2 & $+4^{\circ} \mathrm{C}$ de 30 gün katlama & 20 Ocak 2015 \\
\hline 3 & $\begin{array}{l}\text { Açık hava koşulları altında } 60 \text { gün } \\
\text { katlama }\end{array}$ & 20 Şubat 2015 \\
\hline 4 & $+4^{\circ} \mathrm{C}$ de 60 gün katlama & 20 Şubat 2015 \\
\hline 5 & $\begin{array}{l}\text { Açık hava koşulları altında } 90 \text { gün } \\
\text { katlama }\end{array}$ & 20 Mart 2015 \\
\hline 6 & $+4^{\circ} \mathrm{C}$ de 90 gün katlama & 20 Mart 2015 \\
\hline $\begin{array}{l}7 \\
\text { (Kontrol) }\end{array}$ & $\begin{array}{l}\text { Toplanır toplanmaz hiçbir işlem } \\
\text { uygulanmadan doğrudan ekim }\end{array}$ & 20 Aralık 2014 \\
\hline
\end{tabular}

Ekimler yapıldıktan sonraki 7. günden itibaren gözlemlere başlanmış ve her haftanın pazartesi günleri haftada bir gün olmak üzere 90 gün boyunca gözlemlere devam edilmiştir. Çimlenme 2015 yılının Mart ayı başında başlayıp, 2015 yılının Mayıs ayı ortasına kadar sürmüştür. Bu süreçte, her bir işleme ait çimlenmeler ayrı ayrı sayılarak kayıt altına alınmıştır. Çimlenmeler tamamlandıktan sonra işlemlere ait ortalama çimlenme yüzdeleri hesaplanarak elde edilen veriler SPSS istatistik paket programında (SPSS Inc. 1998) değerlendirilmiştir.

\section{BULGULAR}

Yapılan ölçüm ve değerlendirmeler sonucunda araştırmaya konu olan Burdur-Bucak orijininden toplanan Derici Sumağı tohumlarında $1 \mathrm{~kg}$ meyve örneğinde ortalama 40000 meyve, $1 \mathrm{~kg}$ tohum örneğinde ise ortalama 74000 tohum bulunduğu ortaya çıkmıştır. Ortalama tohum 1000 tane ağırlığı 13.50 gr, tohum doluluk oranı ise \%54.44 olarak belirlenmiştir. Yine, ortalama meyve eni $2.74 \mathrm{~mm}$; ortalama tohum eni ise $1.84 \mathrm{~mm}$ olarak tespit edilmiştir.

Varyans analizi sonuçlarına göre, uygulanan işlemlerin çimlenme yüzdesi bakımından $p<0.01$ önem düzeyinde birbirlerinden farklı oldukları ortaya çıkmıştır (Tablo 2).

Tablo 2. Denemeye alınan işlemlere ait varyans analizi sonuçları

\begin{tabular}{lllll}
\hline $\begin{array}{l}\text { Varyasyon } \\
\text { Kaynağı }\end{array}$ & $\begin{array}{l}\text { Serbestlik } \\
\text { Derecesi }\end{array}$ & $\begin{array}{l}\text { Kareler } \\
\text { Ortalaması }\end{array}$ & F Oranı & $\begin{array}{l}\text { Önem } \\
\text { Düzeyi }\end{array}$ \\
\hline İşlem & 6 & 1.253 & 4.126 & $0.009^{* *}$ \\
Tekerrür & 3 & 0.242 & 0.797 & $0.512 \mathrm{~ns}$ \\
Hata & 18 & 0.304 & & \\
\hline
\end{tabular}

**: 0.01 olasılık düzeyinde farklı, ns: i̇statistiksel olarak fark yok

Yapılan Duncan testi sonucuna göre, en yüksek ortalama çimlenme yüzdesi (\% 34.0) beş nolu işlemde (90 gün doğal koşullarda katlamaya alınıp ekilen tohumlarda), en düşük ortalama çimlenme yüzdesi ise (\% 17.5) altı nolu işlemde (90 gün $+4^{\circ} \mathrm{C}$ de katlamaya alındıktan sonra ekilen tohumlarda) elde edilmiştir. En yüksek çimlenmenin olduğu beş nolu işlemi sırasıyla 3, 1, 4, 2 ve 6 nolu işlemler izlemiştir (Tablo 3; Şekil 1). 
Tablo 3. Duncan testi sonuçları

\begin{tabular}{lll}
\hline işlem No & Çimlenme Yüzdesi & \\
\hline 5 & 34.0 & $\mathrm{~A}$ \\
3 & 28.5 & $\mathrm{AB}$ \\
1 & 26.0 & $\mathrm{ABC}$ \\
7 (Kontrol) & 24.0 & $\mathrm{BC}$ \\
4 & 21.0 & $\mathrm{BC}$ \\
2 & 19.5 & $\mathrm{BC}$ \\
6 & 17.5 & $\mathrm{C}$ \\
Genel & 24.4 & \\
Ortalama & & \\
\hline
\end{tabular}

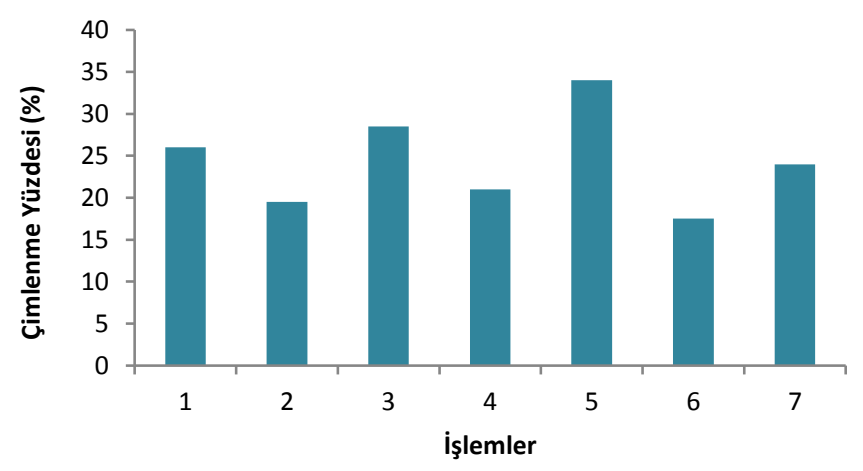

Şekil 1. Denemeye alınan işlemlere ait ortalama çimlenme yüzdeleri

\section{TARTIŞMA ve SONUÇ}

Katlama şekli ve süresinin çimlenme üzerine etkilerinin belirlemek amacıyla uygulanan işlemler arasında istatistiksel olarak anlamlı farklılıklar ortaya çıkmıştır. Buna göre, en yüksek çimlenme (\%34.0) 5 nolu işlemde (Açık hava koşulları altında 90 gün katlama) elde edilmiş olup, bunu sırasıyla 3 nolu (Açık hava koşulları altında 60 gün katlama), 1 nolu (Açık hava koşulları altında 30 gün katlama), 4 nolu $\left(+4^{\circ} \mathrm{C}\right.$ de 60 gün katlama), 2 nolu $\left(+4^{\circ} \mathrm{C}\right.$ de 30 gün katlama) ve 6 nolu işlemler $\left(+4^{\circ} \mathrm{C}\right.$ de 90 gün katlama) izlemiştir. $\mathrm{Bu}$ sonuçlardan hareketle, araştırmaya konu olan Derici Sumağında ekim alanının ve iklim koşullarının uygun olmaması nedeniyle erken ekim yapmanın mümkün olmadığı yerlerde ya da dönemlerde tohumların ekimden önce katlama ihtiyacı olduğunu söylemek mümkündür. Hatta tohumların açık alan koşulları altında doğal katlamaya alınması $+4^{\circ} \mathrm{C}$ de soğuk ortamda katlanmasından daha etkili ve iyi sonuç verebileceği söylenebilir. Eğirdir orman fidanlığında aynı türde daha önce gerçekleştirilen bir araştırmada sera ve açık alanda değişik örtüleme şekillerinin çimlenme üzerine etkileri araştırılmış ve yaklaşı $\% 15-60$ arasında değişen oranlarda çimlenmeler elde edilmiştir (Yücedağ vd. 2010). Bu araştırma çalışmasında ise elde edilen en yüksek çimlenme $\% 34$ olarak tespit edilmiştir. Bu sonucun, denemede kullanılan tohumların doluluk oranlarının \%54.44 olduğu dikkate alındığında aslında boş tohumların uzaklaştırılması ile ilgili bir ön işlemden geçirildikten sonra daha da yükseltilebileceği anlamına gelmektedir. En azından yeni araştırma sonuçları elde edilinceye kadar Eğirdir Orman Fidanlığında yürütülen fidan üretim çalışmalarında tohumların toplandıktan sonra doğal koşullarda 90 gün katlamaya alındıktan sonra ekilmesi uygun olacaktır.

Katlamanın tohum çimlenmesi üzerine önemli etkilerin olduğunu belirten Ürgenç (1992), birçok bitki türünün tohumla üretiminde çimlenme engelini gidermek için tohumların etli kısımlarından ayrılması gerektiğini ve türüne göre 1-5 ay katlamaya tabi tutulması gerektiğini belirtmiştir.

Araştırma süresince ekilen tohumlardan gelişen fideciklerin önemli bir kısmı damping-off nedeniyle zarar görmüş ve ölmüştür. Dolayısıyla fidan üretim çalışmaları sırasında damping-off'a karşı da tedbirler alınmalıdır.

Derici Sumağı, gerek ormanlarımızın biyolojik çeşitliliğine yaptığı katkı ve gerekse çok estetik formları ve ekstrem koşullara dayanıklılıkları nedeniyle son derece önemli bir türdür. Fakat bu türe bugüne kadar yeterince önem verilmemiştir. Bu süreçte hazırlanan 2014- 2018 yıllarını kapsayan yabanıl meyveli türler eylem planında da vurgulanan, ormanlardaki yabanıl meyveli türlerin miktarının azalmakta olduğu ve yaban hayatı açısından dengenin bozulmaya başladığı görülmektedir. Yabanıl meyveler, ormandaki bütün canlılar için doğrudan besin olarak kullanılmakla birlikte insanlar için de sağıklı bir besin kaynağını oluşturmaktadır. Bu bitkilerin meyveleri içerdikleri maddeler gereği şifa özelliği taşımakta, ilaç ve kozmetik sanayisinde de yaygın olarak kullanılmaktadır. Aynı zamanda yabanıl meyveli türlerin yoğun olduğu bölgelerdeki vatandaşların bu ürünlerden ekonomik anlamda faydalanmaları ve belirli bir oranda gelir elde etmeleri de söz konusudur.

Bu nedenle, fonksiyonel ormancılık çalışmalarında önemli bir yere sahip olacağı düşünülen bu türün zaman kaybetmeden yetiştirme teknikleri ile doğal yetişme 
ortamı istekleri daha kapsamlı ve ayrıntılı olarak araştırılmalıdır. Hatta fidanlıklarda pek fazla üretimi yapılmayan Derici Sumağının kültüre alınarak çoğaltılması için Üniversiteler ve Belediyeler ile işbirliği yapılmalıdır. Yayılış gösterdiği alanlarda yöre halkı, türün tanınması ve korunması konusunda bilinçlendirilmelidir. Bu türün doğal ortamında korunmasına ve fidanlıklarda üretimine ağırlık verilmeli, doğal ortamı dışında da değerlendirilmesine yönelik program, proje ve stratejiler geliştirilmelidir.

\section{TEŞEKKÜR}

Bu çalışma, Süleyman Demirel Üniversitesi Fen Bilimleri Enstitüsü Orman Mühendisliği Anabilim Dalı’nda tamamlanan "Katlama Sürelerinin Derici Sumağı (Rhus Coriaria L.) Tohumlarının Çimlenmesi Üzerine Etkisi” konulu yüksek lisans tez çalışmasının bir bölümünü içermektedir. Çalışma verilerinin toplanması sırasında emeği geçenlere teşekkür ederiz.

\section{KAYNAKLAR}

Bewley JD \& Black M (1994) Seeds: physiology of development and germination. Plenum press, New York

Göktürk A (2005) Artvin Çoruh Vadisi Boyunca Doğal Olarak Yayılış Gösteren Bazı Ağaç ve Ağaççık Türlerinin Tohumlarının Çimlenme Engellerinin Giderilmesine Yönelik Çalışmalar. Kastamonu Üniversitesi Fen Bilimleri Enstitüsü Yüksek Lisans Tezi. 155 s. Artvin
ISTA (1996) International Rules for Seed Testing. Seed Sci. \& Technol. (Supplement), 24:1-335

Leadem C (1996) A guide to biology and use of forest tree seeds. B.C. Ministry of Forests. Victoria, BC. 20 p

Ölmez Z, Temel F, Göktürk A ve Yahyaoğlu Z (2007) Effect of cold stratification treatments on germination of drought tolerant shrubs seeds. Journal of Environmental Biology, 28 (2):447-453

Rietveld WJ (1989) Variable Seed Dormancy in Rocky Mountain Juniper, (Ed. Lveis, T.), Proceedings, Intermountain Forest Nursery Association, USDA- Forest Service, Forest and Range Station, RM-184, Fort Collins, CO

SPSS Inc (1998) SPSS for Windows. Released 10.0, SPSS Inc., Chicago, IL., USA

Serez M ve Eroğlu M (1993) Orman Alanlarının Korunması Açısından Ormancılık Mevzuatı Üzerine Bir Değerlendirme, Orman Bakanlığı ı. Ormancılık Şurası, Tebliğler ve Ön çalışma Grubu Raporları, Cilt 3, Seri No : 13, Yayın No: 006, 277 - 284s., Ankara

Ürgenç S (1992) Ağaç ve Süs Bitkileri - Fidanlık ve Yetiştirme Tekniği İstanbul Üniversitesi, Üniversite Yayın No.3676, Fakülte Yayın No.418, İstanbul

Ürgenç S (1998) Ağaçlandırma Tekniği, İstanbul Üniversitesi Rektörlüğü Yayın No: 3994, Orman Fakültesi Yayın No: 441, İstanbul

Yahyaoğlu Z (1997) Ağaçlandırma Tekniği Ders Notu Üçüncü Baskı, Karadeniz Teknik Üniversitesi, Orman Fakültesi Ders Teksirleri Serisi:44, Trabzon

Yılmaz F (1994) Kızılçam (Pinus brutia Ten.) Tohumlarında Kabuktan Kaynaklanan Çimlenme Engelinin Kimyasal Ön işlemlerle Giderilmesi, Yüksek Lisans Tezi, Karadeniz Teknik Üniversitesi Orman Fakültesi, 55s., Trabzon

Yücedağ C, Gültekin HC ve Pırlak iT (2010) Sera ve Açık Alanda Sumak (Rhus coriaria L.) Tohumları Çimlenmesi Üzerine Ekim Zamanı ve Örtülemenin Etkileri. Süleyman Demirel Üniversitesi Orman Fakültesi Dergisi, 9-15.. 